\title{
Sobre José Antonio Maravall (1911-1986) y sobre la historiografía española
}

\author{
FRANCISCO ABAD \\ UNED \\ fabad@flog.uned.es \\ Recibido: marzo de 2011. Aceptado: abril de 2011
}

\begin{abstract}
Resumen: Este artículo sitúa la obra de José Antonio Maravall en la historiografía española del siglo XX y analiza su sentido; añadimos un apéndice documental.
\end{abstract}

Palabras clave: José Antonio Maravall, Jaume Vicens Vives, Ramón Menéndez Pidal, Manuel Gómez-Moreno, Américo Castro, generación musical del 27.

Resum: Aquest article situa l'obra de José Antonio Maravall dins la historiografia espanyola del segle XX i n'analitza el significat; hi afegim un apèndix documental.

Paraules clau: José Antonio Maravall, Jaume Vicens Vives, Ramón Menéndez Pidal, Manuel Gómez-Moreno, Américo Castro, generació musical del 27.

\section{Generaciones intelectuales en la Baja Edad Contemporánea española}

Se cumplen ahora cien años del nacimiento del profesor e investigador José Antonio Maravall Casesnoves, maestro impar —en más o menos la segunda mitad del siglo XX - especialmente en cuestiones de la Edad Moderna, y en Historia del pensamiento político y social español.

Vamos a referir a nuestro autor al conjunto de nuestros historiadores de bastante a fines del Ochocientos y de buena parte del siglo $\mathrm{XX}$, y procuraremos caracterizar a algunos y desde luego a él mismo.

Las generaciones culturales de la España de la Baja Edad Contemporánea son -en lo que nos importa ahora, y según los nombres con que se las conoce-, las del 98, del 14, del 27 y del 36; el espacio de fechas del nacimiento respectivo de sus miembros son las de 1861-1875; 1876-1890; 1891-1905; y 1906-1920. Desde luego en las letras bellas, en la filosofía, en la filología, resultan claramente estas datas: por ej. Amado Alonso y Dámaso Alonso pertenecen de manera nítida al Veintisiete, y así ambos fueron críticos literarios con bastante de formalismo, y el segundo se inició además como poeta puro; todo el mundo sitúa a don José Ortega y a Manuel Azaña en la llamada «generación del 14»; etc. 
Algunos nombres de historiadores adscritos a tales sucesivas generaciones
son:

— Generación del 98: Rafael Altamira; Ramón Menéndez Pidal; Manuel Gómez Moreno.

- Generación del 14: Antonio Ballesteros Beretta; Américo Castro —originariamente y a la vez filólogo, catedrático en España de «Historia de la lengua española»; Ramón Carande.

— Generación del 27: Claudio Sánchez Albornoz (nacido en 1893); Melchor Fernández Almagro, asimismo estudioso de las letras y crítico literario en la prensa.

- Generación de 1936: sus miembros nacieron como está dicho entre 1906 y 1920: José Antonio Maravall lo hizo el 12 de Junio de 1911; otros historiadores coetáneos fueron nada menos que José María Lacarra; Antonio Domínguez Ortiz; Jaume Vicens Vives; Julio Caro Baroja; Manuel Tuñón de Lara; Joan Reglà; José María Jover; ...

Por supuesto a estas sucesivas cuatro generaciones se hallan adscritos literatos bien conocidos, filósofos, músicos, etc.; resultan menos conocidos quizá los músicos, sobre cuya específica «generación del 27» nos permitimos apuntar una ilustración.

\section{Un excurso sobre la generación musical del 27 catalana y madrileña}

Federico Sopeña hace referencia ya en su Historia de la música española contemporánea a la que todavía estaba denominada «la llamada «generación de 1931», y enumera a «Salvador Bacarisse, Rodolfo Halffter, Gustavo Pittaluga, [...] Fernando Remacha y Julián Bautista» en tanto «el grupo español cuya música llena los conciertos desde la Dictadura [de 1923] hasta el comienzo de la guerra»; de otro lado y poco más tarde, incluso se aplicó a los pintores españoles de hacia 1925-1935 la denominación de «generación artística del centenario de Góngora» o «generación plástica del centenario de Góngora»: lo hace José María Moreno Galván en el año 1960.

En lo que se refiere a la misma música, vemos al compositor y musicólogo catalán Manuel Valls Gorina referirse a los Halffter, Bacarisse, Pittaluga, Adolfo Salazar, en tanto «el componente musical» de igual generación a la que pertenecían Alberti, Salinas o Lorca, y a tal cohorte la denominará «generación de la República». La lista de las personalidades del 27 poético — manifiesta a la letra- «tiene su equivalente sonoro» en las realizaciones de los Halffter, de Bacarisse, de Remacha, de Julián Bautista, de Joaquín Rodrigo, etc., y «en el sector plástico», en las figuras de Dalí, Miró, Benjamín Palencia, ...

En el año 1972 se editaron en forma de artículo de semanario unas declaraciones orales de Cristóbal Halffter con el título periodístico de «Una generación frustrada: los músicos del 27», y en él Halffter habla de «la llamada «generación del 27»»; en tales declaraciones repite de manera natural una y otra vez la fór- 
mula «generación del 27». Tiene por del 27 a Julián Bautista, Salvador Bacarisse, Gustavo Pittaluga, Rodolfo y Ernesto Halffter, Joaquín Rodrigo, Roberto Gerhard, Ros[a] García Ascot, Fernando Remacha y a «algunos otros».

De su parte y con posterioridad, Tomás Marco emplea la fórmula de manera natural, como algo ya estandarizado y más o menos establecido: «Se llama Generación del 27 - escribirá así-, por homologación a la generación poética del mismo nombre, a una serie de compositores nacidos en los alrededores de 1900, que iniciaron su carrera en los años veinte [...]. Lo más granado de la generación se aglutina en Madrid en 1930 con el nombre de Grupo de los Ocho».

Los «Ocho» de Madrid eran los ya mencionados en su mayoría Juan José Mantecón, Fernando Remacha, los dos Halffter, Julián Bautista, Gustavo Pittaluga, Rosa García Ascot y Salvador Bacarisse; de ellos Pittaluga nació ligeramente más tarde de la zona de fechas a que corresponde la generación, en 1906. Marco concluye con que es [...] útil el título de Generación del 27, con la ventaja de ser el mismo que el de una generación literaria con la que estos autores guardan una asombrosa similitud, y con la que colaboraron en numerosas ocasiones. Por otro lado el Centenario de Góngora de 1927 [...] fue también decisivo para el lanzamiento de estos compositores.

En la estimación de nuestro autor, «el principal compositor de esta generación y el más difundido a escala internacional fue [el tarraconense] Roberto Gerhard», el compositor español del siglo XX — añade aún- de mayor relieve tras Manuel de Falla.

Para el presente musicólogo Tomás Marco la generación se halla «fundamentalmente constituida por el Grupo de Madrid [... y también ] por el Grupo Catalán», aunque tampoco se puede olvidar a otros compositores coetáneos como por ej. Pablo Sorozábal, Jacinto Guerrero, Joaquín Rodrigo, etc.).

\section{A. Gallego asimismo habla de generación musical "del 27"}

\section{La generación de J. A. Maravall: la generación del 36}

De manera temprana - hacia finales de los pasados años cincuenta- y en referencia a lo literario y en particular a lo lírico-, José Luis Cano habla ya decididamente a la vez que de generación del 27, de «generación poética de 1936», de «generación del 36», o «generación de 1936», y lo hace de manera adecuada cronológicamente, lo que no han hecho otros autores, en particular por lo que se refiere a la segunda de esas denominaciones, la «del 36». El volumen un poco posterior de nuestro autor Poesía española del siglo XX organiza por igual una de sus partes con la designación global de «La generación de 1936», y en la misma se agrupan los análisis sobre José Antonio Muñoz Rojas, Luis Felipe Vivanco, Gabriel Celaya, etc.

Junto a Cano, crítico honesto y entregado a su labor, más persona de dignidad civil durante el franquismo, fue Ricardo Gullón el otro adelantado en hablar de generación del 36 tal como hoy la entendemos. Aunque Gullón ya había alu- 
dido antes al asunto, fue en un artículo suyo de 1959 en el que plantea la cuestión de manera expresa y la expone con detalle. Don Ricardo escribe efectivamente unas páginas inteligentes sobre «La generación de 1936»: denomina aún a los del veintisiete «la generación de 1925» (y los denominará creemos que siempre o casi siempre), y enumera entre los miembros del 36 a los que hoy tenemos por tales, es decir, a Miguel Hernández, Luis Rosales, los Panero, Vivanco, etc. (poetas), y José Antonio Maravall — poeta en la juventud y enseguida ensayista e historiador-, José Ferrater Mora, el propio Ricardo Gullón, ... (prosistas).

Mantiene además que «por debajo de diferencias evidentes, de disparidades inocultables y del hecho de haber tomado parte en la contienda desde contrario bando, las gentes de la generación del 36 tienen mucho de común, y se parecen entre sí más de lo que pueden parecerse a los integrantes de generaciones anteriores [...]. El hecho generacional y paradójicamente aglutinador es la guerra civil [..., pues lo padecieron directamente y desde cerca: algunos murieron; otros sufrieron prisión y no pocos vivieron o viven en el destierro».

A la vista de los datos anteriores, hemos de decir que quizá el autor más decisivo en proponer y estandarizar las fórmulas verbales «generación del 27» y «generación del 36» fue el atento y mesurado crítico literario José Luis Cano, sin que ello nos haga desconocer el papel jugado — respecto de la primera acuñación- por Juan Chabás y por Valbuena, y el de Gullón respecto de la segunda.

La revista Ínsula dedicó una parte monográfica a esta «generación del 36» en el número doble 224-225 de 1965. Aparece allí una encuesta, y por ej. José Luis Aranguren manifiesta que sus miembros tomaron parte más o menos activa o más o menos pasiva en la guerra civil, pero que de cualquier manera «no se entregaron totalmente a ella o, ulteriormente, supieron superarla en lo íntimo de sí mismos».

En la página 30 de ese número y ordenado por la redacción de la revista, figura un recuadro con una «Nómina muy incompleta y controvertible de la generación del 36», que debe verse en todo caso. Por nuestra parte creemos que la generación es la de los nacidos entre 1906 y 1920, según queda apuntado ya en el presente y otros escritos nuestros. Entre los críticos y estudiosos de la literatura se menciona allí a Guillermo Díaz-Plaja, Martín de Riquer, José Manuel Blecua, Rafael Lapesa, Emilio Orozco, Antonio Tovar, Rodríguez Moñino, Luis Sánchez Granjel, Alonso Zamora..., de diversa envergadura intelectual y los dos primeros bien representativos de la cultura catalana, más el tercero aragonés que ha rehecho su vida en Barcelona, al igual que les ocurre a sus dos hijos asimismo filólogos; Lapesa fue desde luego el mejor lingüista del grupo, y se especializó sobre todo en dialectología histórica y en sintaxis histórica, a más de en historia externa del idioma, y llevó a cabo además análisis literarios de todas las épocas. Entre los historiadores mencionados por Ínsula cabe echar en falta el nombre señero y fundamental por su trascendencia de Jaume Vicens Vives.

La formación y cristalización del concepto y de la fórmula verbal generación del 36 se encontraban lo suficientemente cuajadas por esa mitad de la década del sesenta a la que aludimos, como para que se dedicase un congreso a la materia, hecho en «Homenaje a Homero Serís» hacia finales de 1967; sus resultados es- 
critos aparecieron en la revista Symposium del verano del año siguiente. Este encuentro reunió a un cierto número de los propios miembros del 36: José Luis Aranguren acepta la denominación, aunque a regañadientes; José Ferrater Mora cree que la guerra civil constituyó para estos hombres y mujeres un eje histórico, lo que había dicho a su manera Aranguren y mantuvieron asimismo varios de los congregados. Extraña mucho no obstante que don Antonio Rodríguez Moñino dijese entonces en referencia a Serís, que «antes que nadie - y esta fortuna no podrá disputársele- señaló el hecho literario [de la existencia de una generación del 36,] y supo encerrar en el aprisco de una raya circular de tinta los nombres destacantes y su significación de grupo»; don Antonio parece no haber leído de verdad las breves páginas del homenajeado, o no las recuerda, pues ciertamente don Homero denominaba con la designación del 36 a una amalgama de autores, y fundamentalmente a los del Veintisiete (cfr. Symposium, XXII/2, 1968; materiales de este número más otros nuevos aparecen en lengua inglesa en el volumen editado por Jaime Ferrán y Daniel P. Testa, Spanish Writers of 1936, London, Támesis Books, 1973).

Un nuevo escrito posterior de R. Gullón, se rotuló también «La generación del 36». Estamos ante una redacción en parte nueva del trabajo del año 59, y en él delimita su autor las fechas de nacimiento de los escritores del 36 entre 1906 y 1914; ya queda repetido cómo personalmente proponemos que se entienda esa zona de fechas entre 1906 y 1920, para guardar así los 15 años de la teoría ortodoxa de las generaciones (cada hornada nace en algún momento de un intervalo de quince años, y actúa fundamentalmente con su perfil característico durante treinta o más).

Debe saberse que una antología denominada La generación poética de 1936 y hecha por Luis Jiménez Martos, apareció en Barcelona en 1972. El antólogo, por su cuenta y de acuerdo con lo que era ya costumbre, identifica a los escritores del 36 en tanto nacidos de 1905 a 1915; antes de que se manifestase Homero Serís - dice por su lado- «era visible la presencia en España de un grupo de poetas e intelectuales con marchamo de grupo», y enumera a Rosales, Leopoldo Panero, Vivanco, Ridruejo, Laín y José Luis Aranguren. Por lo menos el segundo, el quinto y el sexto de ellos fueron amigos personales de Maravall.

En fin y como un hecho intelectual normal y establecido, Francisco Pérez Gutiérrez hizo para Taurus otra Antología poética de La generación de 1936 (1976), en la que incluía a los Panero, Miguel Hernández, Celaya, Arturo Serrano-Plaja (el padre del estudioso Carlos Serrano)...

Nosotros creemos que debe ampliarse a otros campos de la vida intelectual este nombre de "generación del 36» surgido en la poesía; la generación de no poetas a la que nos referimos ha resultado fundamental en el desarrollo de las ciencias humanas en aproximadamente la segunda mitad del siglo XX en España. En todo caso José Antonio Maravall fue asimismo poeta en la juventud, y amigo de poetas (Juan Ramón Jiménez, Leopoldo Panero).

Esta generación española del 36 enlaza más bien con la del 14 que con la del 27, es menos formalista y estetizante que la de la Vanguardia, y de contenidos de ideas como la de 1914. 


\section{En la traza de Rafael Altamira y de Manuel Gómez Moreno}

Del Noventayocho ya hemos señalado a Altamira, Menéndez Pidal y Gómez Moreno. Los tres mantuvieron contacto próximo, y uno u otro incidió en la obra de los demás de entre ellos y en autores más jóvenes.

Altamira propuso y llevó a cabo la materia Historia de la civilización, y no resultó ajena a ella Menéndez Pidal: el joven Ramón la tuvo muy presente al componer el «Vocabulario» del Poema de Mio Cid, lleno de preciosas observaciones culturales sobre la vida toda española del siglo XI; ese texto del Cid se estima por los mejores especialistas de nuestros días que es de hacia finales de la centuria, lo que es compatible con la antigua idea de Hinojosa de que refleja institucionalmente el estado de algunas de esas instituciones a mitad de siglo (el XI).

Altamira creemos nosotros que incidió con toda probabilidad en el joven Ramón Menéndez Pidal; esta idea la ha considerado un colega temeraria, «aventurada» —expresa él一, pero no parece así: dada la especialización un tanto bárbara (que hubiera dicho Ortega) de nuestros días, pensamos que ese estimado compañero de oficio no ha estudiado a don Rafael, y no sabe acaso cuál es su significación historiográfica, ni que Altamira y don Ramón colaboraron juntos en al menos una misma revista, y que sobre todo se hallaron juntos en la Junta para Ampliación de Estudios, etc.

Un análisis somero de las obras de Rafael Altamira hace saltar a la vista su integración o fusión de la Historia política con la institucional y cultural — dicho sea así para entendernos-; en este caso queremos contar asimismo con la autoridad de uno de sus principales estudiosos, el también coetáneo de Maravall — aunque algo más joven - José María Jover, quien tiene escrito:

Corresponde a Rafael Altamira el mérito de haber derribado, en el marco de la historiografía española, las barreras que tradicionalmente venían separando la «historia interna» de la «historia externa», y ello medio siglo antes de que la renovación experimentada por los estudios históricos en los años cincuenta de nuestro siglo viniera a terminar, desde su raíz, con tal dicotomía (Jover 1992: 307).

Resulta algo bastante elemental saber que fue Altamira quien hacia finales del Ochocientos y a inicios de la centuria del XX derribó ciertamente esas barreras entre lo llamado externo y lo llamado interno en historia, y esto creemos debe ponerse en relación con la obra pidalina; desde luego Menéndez Pidal pasó de eso externo - entendamos que en lingüística eran las leyes fonéticas, etc.— a lo interno — la diferenciación geográfica y cronológica, la estratificación socio-cultural—, y también don Ramón gustó del estudio de las civilizaciones (el Islam peninsular). El manual pidalino de Gramática histórica es bastante «externo», si vale decirlo así: leyes, procesos fisiológicos, procesos acústicos, ...; el libro sobre la leyenda de los Infantes de Lara, los volúmenes sobre el aludido Poema de Mio Cid, la obra lingüística magna en torno a los orígenes próximos de lo que luego será el idioma español, etc., resultan textos con un componente de estudio que podemos deno- 
minar «interno», atento a lo histórico y a lo cultural. Cuando don Ramón pasa de interpretar las leyes fonéticas como tales regularidades fonéticas a interpretarlas en tanto gustos lingüísticos de un grupo social, se halla apelando a lo «interno», a la libertad del hablante que no es la de los neogramáticos, sino la de Vossler, o la que en la huella del maestro de Munich teorizaría Coseriu.

José María Jover señala asimismo cómo en una serie intelectual muy aproximada a la de Rafael Altamira se moverían andando los decenios Vicens y Maravall, por lo que enuncia:

a) «Muy cerca de la historia de la civilización tal como la entendió Altamira y tal como podría ser definida en nuestro tiempo, queda el proyecto de Historia que propugna Vicens (Jover1992: 327).

b) «José Antonio Maravall propugna una historia del pensamiento muy relacionada con la evolución de las sociedades respectivas [...., y dedicó su carrera de historiador], en buena parte, al análisis de lo que generalmente se entiende por «mentalidades»» (Ibid., 330 y 360).

Por otra parte tenemos propuesto que se entienda que Iglesias Mozárabes de Gómez Moreno (1919), y Orígenes del español (1926) de don Ramón resultan obras coherentes y relacionadas entre sí: ambas son enormemente eruditas, ambas se ocupan de lo mozárabe, la segunda acaso se halló estimulada en su composición por la primera, ambas tienen presente la geografía y la cronología ... Estas similitudes las creemos ciertas, aunque se distinguen en que la de Menéndez Pidal contiene doctrinas teóricas, mientras la de don Manuel es más bien empírica y descriptiva; las páginas teóricas de don Ramón han pasado a formar parte de los textos clásicos de la romanística.

En realidad lo mismo Iglesias Mozárabes que Orígenes del español constituyen aportaciones a la historia de la civilización española en la Alta Edad Media, e insisten en una realidad mozárabe sobre la que escribiría un tercio de siglo más tarde Maravall, en el contexto de una de sus monografías más celebradas, la de El concepto de España en la Edad Media; Menéndez Pidal y Gómez Moreno nos parecen impregnados por algunas perspectivas de la historiografía de Rafael Altamira, y a su vez don Ramón y don Manuel se asemejan en sus descripciones eruditas de hechos, en el gusto por lo medieval y lo renacentista, en el trazar referencias a los documentos arquitectónicos o librescos y catalogarlos, etc.: ambos fueron figuras de relieve en las respectivas Secciones que encabezaron en el «Centro de Estudios Históricos» de la Junta para Ampliación de Estudios.

Como queda apuntado, José Antonio Maravall tiene un capítulo de su libro recién aludido que se dedica a «La cultura mozárabe como conservación del estado que precedió a la invasión islámica»; sitúa tal cultura entre 711 y 1037 (nacimiento del Reino de Castilla) - aunque él lo dice con otras palabras (Maravall 1981: 161) — y avalora lo mozárabe en cuanto «el factor mozárabe como sustrato hispánico», tesis que él enuncia así:

[La] profunda tendencia conservadora de la cultura mozárabe permite que podamos adscribir a ésta el mantenimiento del concepto mismo de España en 
medio de los dramáticos avatares de nuestra Edad Media. Mozarabismo, [...] es decir, tradición hispano-romano-visigoda vertida en el molde de la nueva situación histórica nacida de la invasión árabe, la cual es en definitiva el fundamento del programa político de nuestra Edad Media. Y sólo así se explica que al término de ésta, la España de los Reyes Católicos sea saludada por Juan Margarit, por Nebrija, por tantos otros, como una restauración de aquella tradición antigua» (Ibid., 190; el subrayado es nuestro).

Maravall remite además sobre la impronta del mozarabismo a un pasaje que había escrito Vicens en la primera edición (1952) de su Aproximación a la Historia de España, en la que señalaba —en la traza expresamente declarada de Gómez Moreno- cómo el mozarabismo constituyó «un factor esencial en la vida histórica española» en los siglos VIII a X, ya que los mozárabes «mantuvieron frente a los musulmanes el legado de Roma» (Vicens 1952: 4546); no obstante en la segunda y ya última Aproximación a la Historia... suya (1960) manifiesta otra idea: la de que el mozarabismo resulta en todo caso «un factor que no debe descuidarse al apreciar la vida histórica española» en las tres centurias primeras de la dominación musulmana, pero que cabe aminorar la «disminución del papel atribuido a los mozárabes como elemento disidente en el Sur y nacionalista en el Norte» (Vicens 1974: 56 y 187). José Antonio Maravall mantuvo sin embargo la referencia literal al primer Jaume Vicens, y subrayó por igual que al mozarabismo más primitivo y estricto, «hemos de añadir aquellas corrientes históricas posteriores — - legitimismo astur, neogoticismo, tradicionalismo leonés, etc., etc.- - que son un rebrote vigoroso de la concepción hispánica que los mozárabes desarrollaron» (Maravall 1981: 191); el componente mozárabe de la historia española puede decirse -interpreta- que ejerció «una acción sustratística», dado que (por analogía de lo que es un «sustrato» en lingüística), «cuando la población mozárabe decae, eliminada por los hispano-musulmanes o absorbida por los cristianos del norte, en la historia de éstos rebrotan tendencias que arrancan de aquella primera capa, cuya civilización, cuyas concepciones históricas habían sido sofocadas» (Ibid.).

Don Manuel Gómez Moreno ha incidido con su historiografía — creemos nosotros, y en particular por sus Iglesias Mozárabes - en su coetáneo Menéndez Pidal, en Jaume Vicens, en José Antonio Maravall, en la historiografía del Arte, etc.: un hombre del 98 deja su impronta en su propia generación o en la del 36.

A su vez Menéndez Pidal no fue un autor ajeno para don José Antonio; a $E l$ concepto de España en la Edad Media subyace por ej. —nos parece- esta afirmación pidalina, escrita en su teorización sobre los visigodos «Universalismo y nacionalismo. Romanos y germanos»: «La lucha entre romanismo y germanismo [...] caracteriza muy especialmente la llamada alta Edad Media. [...] En esta edad germanorromana el universalismo imperial desaparece, quedando sólo representado por el universalismo eclesiástico, y surge un sentimiento contrario: el nacionalismo político y cultural» (Menéndez Pidal 1957: 208 y 213). 
El mismo don Ramón habló en su Historia de la lengua española de que ya en la época visigótica se estaba en un proceso de «nacionalización lingüística de España», uniformidad idiomática de la que escapó la innovadora Castilla; desde luego esta llamada «nacionalización» ha de entenderse en el contexto de todos los escritos pidalinos, $\mathrm{y}$ ha sido acaso motivo de caricatura y casi burla por quienes no han percibido la intertextualidad — digámoslo así- o sistema de referencias internas propia de todos los escritos de don Ramón, a quien en verdad se lee muy poco desde hace décadas. En esta Historia de la lengua escribe el maestro que en efecto, «desde los primeros momentos de los reinos germánicos, la provincialización del Imperio tiende a producir una nacionalización de las provincias, asentada sobre cierto particularismo cultural que en cada una de ellas apuntaba» (Menéndez Pidal 2005: 213); así en primer término y ya en el siglo V, el obispo gallego Hidacio, «que hace la historia del desbarajuste económico y administrativo del Imperio y de las devastaciones de suevos, vándalos y alanos, nos da una significativa muestra de cómo avanzaba la nacionalización cultural de la provincia». Y prosigue para ilustrarlo:

En su Crónica imperial (468) Hidacio [...] adopta para los sucesos de España un cómputo [temporal ... ] puramente español, que arranca siempre de un mismo punto fijo, el año de la a e r a 'tributo' (plural de a e s) o año 38 a. C. en que Augusto organizó la tributación del Imperio. [...] Pero la era quedó usual en España hasta la baja Edad Media, como recuerdo de ese primer indicio en el siglo $\mathrm{V}$ de que una cultura hispana se individualizase dentro del Imperio, dotada de vigor bastante para abarcar todo el territorio desde la Lusitania a la Tarraconense, y para rebasarlo luego, cuando la voz era se propagó, con un nuevo sentido, a todos los idiomas europeos desde España (Ibid., 214).

Este nacionalismo (mejor es llamarlo prenacionalismo) ha de entenderse en cuanto hecho opuesto a imperialismo (el romano), y en tanto conciencia visigóticomozárabe que informará (J. A. Maravall) nuestros tiempos de la Edad Media.

Respecto a lo idiomático y lo político cabe añadir con Menéndez Pidal cómo «el uso del [idioma] gótico se mantendría muy vivo hasta Leovigildo [...], y el reino godo se modela[rá] en un concepto estatal unitario, fundamentalmente romano» (Ibid., 218), Estado que - recuerda Luis García de Valdeavellano- «hasta Suíntila (621-631) no pudo completarse [...] al ser expulsado el Imperio de Bizancio» de nuestras ciudades (Valdeavellano 1982: 185; el presente estudioso llevó a cabo una amplia glosa a El concepto de España...: 1955).

\section{Américo Castro y otros autores}

De la generación del 14 quedan mencionados el medievalista — aunque fuese autor de una muy amplia obra general- Antonio Ballesteros; el modernista Ramón Carande; y el filólogo Américo Castro —mas dedicado también a lo historiográfico a partir de hacia 1936; la materia de la que era catedrático «Historia de la lengua española» la atendió poco-. 
Don Américo hizo una especie de lo que más tarde se denominaría Historia de las mentalidades, ya que ciertamente puso en relación las creencias con las actuaciones vitales; lo sentido intelectualmente (en el más amplio y a veces modesto significado de la palabra) con lo actuado en las acciones; las creencias con las conductas.

Américo Castro llegó a interpretar en efecto las sustancias de contenido de las obras literarias - el hacer de algunos escritores-, según el que él creía sistema de juicios o prejuicios sociales; es posible que en verdad algún escritor deje traslucir su angustia social de converso en lo que escribe, pero tal o tales casos posibles no pueden extrapolarse a toda la realidad histórica de España, la cual se halla compuesta de muchos integrantes y complejidades en el espacio y en el tiempo.

Jaume Vicens no llegó a conocer entre nosotros el despliegue de la Historia de las mentalidades — José María Jover, José Antonio Maravall, algunos atisbos en Sánchez Albornoz al contestar a A. Castro, atisbos también en Vicente Palacio Atard, etc.- - pero sí expresó su discrepancia con la identificación de la historiografía con la historia de las ideas sin más, una historiografía sin vinculación a la base estructural socioeconómica o a las diferentes fases de lo histórico fases A y B, expansivas y de contracción respectivamente-...

Vicens discrepó en concreto de Menéndez Pidal, de Américo Castro y de Sánchez Albornoz, de Jover, de Juan Sánchez Montes, esto es, disintió de autores mayores, coetáneos o menores que él, y les atribuía «ideologismo» historiográfico; se da la aparente paradoja de que el Maravall que no en su obra inicial, pero sí más adelante hizo historia social de las mentalidades, discrepó también de don Américo tal como lo hizo Vicens, y Vicens acaso tampoco se mostraba completamente de acuerdo acaso con alguno de los libros iniciales de don José Antonio. Según decimos Vicens se manifestó discrepante de Américo Castro, y un segundo don José Antonio asimismo lo hizo, aunque entre líneas y casi nunca de manera expresa.

José Antonio Maravall se propuso ya en los años sesenta - desde acaso el texto sobre El mundo social de la Celestina- investigar y escribir justamente desde el punto de vista de la Historia social, y de hecho anunció en 1967 un volumen sobre *El problema de la Historia social que es de lamentar no pudiese llevar a término; su impregnación de esta perspectiva sociológica la manifiesta al añadir al referido anuncio estas palabras: «Quizá lo mejor que en su día ofrezca [el libro *El problema de la Historia social] sea la sinceridad con que su tema surgió y ha ido siendo desarrollado, al contenerse en él las reflexiones sobre su tarea de un historiador que viene trabajando en el ambiente intelectual de una Facultad de Ciencias Políticas y Económicas» (Maravall 1967: 10). La sociología, las estructuras socio-económico-políticas, etc., eran asuntos vividos ciertamente en su Facultad, y ello incidió en nuestro autor, que dedicó más tarde quizá su mayor obra a la temática del Estado Moderno y mentalidad social (1972).

Veamos lo que escribía Vicens acerca de una historiografía ideográfica o de hechos minoritarios o superestructurales, y que no habían afectado a totalidades (la coherencia discursiva de nuestras presentes páginas nos obliga a traer a co- 
lación fragmentos de Jaume Vicens que ya hemos transcrito en ocasión anterior, lo que - por resultar necesario- rogamos se disculpe).

Nuestro autor se detiene en la historia de la cultura, y manifiesta en relación a ella: «Claro es que resulta provechoso explorar las capas ideológicas, jurídicas, sentimentales, estéticas, religiosas y morales de un pueblo. No negamos esta utilidad. Lo que negamos es que los «culturalistas» aporten una contribución objetiva al conocimiento del exacto pasado del hombre español. [...] Hasta hoy la historia de la cultura no es más que un estudio de minorías intelectuales, y por lo tanto representa el examen de una microscópica porción de la mentalidad actuante en un determinado período histórico (Vicens 1974: 15).

Lo exacto del pasado consta de muchos componentes, y de geografías y cronologías diferenciadas: Vicens sitúa ese conocimiento más integral exacto del hombre español del ayer, lógicamente no en el conocimiento de unas minorías creadoras de bellas letras, arte, pensamiento, etc., sino en el conocimiento de la vida del hombre común y de esas minorías en cuanto las integraban personas que también eran comunes en muchas horas de cada día: aquí - en lo común de todos, sin prescindir del todo de los logros de las minorías, claro es- reside el objeto formal propio de la ciencia historiográfica. Por supuesto habrá de atenderse a lo estético, lo religioso, etc., pero no cabe llevar a ello - por inadecuado- el centro de gravedad de la investigación; hay que atenderlo también, mas en la búsqueda de la vida histórica tal como es, completa y compleja. Una historiografía de minorías es una labor carente de casi toda adecuación empírica.

En 1952 y ante obras publicadas hacía poco de Menéndez Pidal —El Imperio hispánico y los Cinco Reinos—, de José María Jover («1635»), de Juan Sánchez Montes, etc., Jaime Vicens se manifestaba con palabras que no dejaban lugar a la duda, ya que estaba postulando una historiografía social y económica de la totalidad de los españoles del pasado y del todo de sus actividades y actitudes, intereses inmediatos, pasiones, etc. En la primera edición de la Aproximación... escribe: «En cuanto a la medida ideológica, se puede incurrir en gravísimo error metodológico al afirmar que cinco, diez o veinte intelectuales representan un reinado, una sociedad, una generación, sea cual sea su talla mental. Ni veinte en el siglo XVIII, ni mil en nuestra centuria. [...] En consecuencia, es preciso determinar los intereses que sirve en su ocupación específica, los cuales son en primer término de tipo humano: intereses directos, vinculados al empleo y el cargo; intereses de los clanes de que forma parte; presión material y moral de quienes depende; complejos psicológicos, como rutina, miedo, ambición, envidia; intereses de tipo espiritual concreto, etc.» (Vicens1952: 16-17). Por ej. las disfunciones psíquicas (miedos grandes, inseguridad interior, ambiciones desmedidas) dan lugar en la vida social a conductas desproporcionadas y despiadadas.

Ocho años más tarde nuestro autor varía la redacción del pasaje y rehace así el párrafo, al que da un alcance más genérico y no alusivo en particular a unas obras de las que disiente: «[Por tanto al tratar de dejar establecida una historia ideológica generacional] no se puede incurrir en el defecto de generalizar y decir: «Tal pensaba Zutano, tal pensaban todos»» (Vicens1974: 18). 
De todas formas Vicens vemos que sugiere y llega casi a establecer de manera sólida lo que es la historia de las mentalidades: el análisis de las relaciones de coincidencia o discrepancia y contradicción (y el por qué de ello) entre de un lado las creencias primeras y más inmediatas y las conductas; entre -en algunos casos - el discurso intelectual y literario de una parte, y los intereses - materiales o espirituales - y rutinas, miedos, envidias, ambiciones, $\mathrm{u}$ otra clase de conductas, por otra parte. O sea: las ideas y los hechos en su relación.

«Historia total» o «humanización de la Historia» es fraseología empleada en un momento por Jaime Vicens, quien se manifiesta a la letra en un momento (1958) de los que iban a ser años últimos de su vida: «Por vez primera se quiere saber qué es lo que hay dentro del pasado; pero saberlo de verdad. [...] Nada puede desperdiciarse, en efecto, para la gran tarea de «vivir» el pasado: modas y gustos, ceremonias y diversiones, actitudes culturales y artísticas, estructuras económicas y sociales, presión demográfica... De esta manera se dibuja una historia total. [...]. Y lo que es más, una historia común, sin castas [...]. Esta historia puede contribuir a situar el hombre en lo humano. [...] La historia cambia de signo: el actual es hacia su humanización» (Vicens1967: 507). Estamos ante dos objetivos: una Historia que sea común, de las más amplias gentes de la sociedad, que incluya a todos y no sólo a las llamadas (por Américo Castro) castas (minoritarias); y una historia total, o sea, integral, comprehendedora de lo complejo. Curiosamente don Américo entendía que la Historia estructural y socioeconómica resultaba deshumanizada, y así se lo reprochó en palabras poco medidas a Braudel, mientras Vicens -instalado en el espíritu de Braudel - estimaba deshumanizado lo que hacía A. Castro, justamente por prescindir de las más de las gentes, y de las estructuras y del flujo de la temporalidad cambiante.

En verdad don Américo escribió de historia, pero no parece que se preparase específicamente para ello cuando decidió hacerlo: la realidad histórica nacional es amplia y compleja, tiene muchos momentos temporales y muchas geografías diferenciadas, y no cabe reducirla a unos hechos que pueden ser verdad, pero que no son todos los que han de considerarse.

Jaime Vicens insistió en una cierta desestima profesional por lo que denominaba «ideologismo», y así escribió en un momento: «Un centenar de datos esparcidos, doscientas frases cogidas al vuelo, son otros tantos insignificantes sondeos en el profundo y desconocido piélago del pasado. [...] Despreciamos el materialismo por unilateral, el positivismo por esquemático, el ideologismo por frívolo. Intentamos captar la realidad viva del pasado, y en primer lugar, los intereses y las pasiones del hombre común» (Vicens1967: 526-528).

$\mathrm{Al}$ escribir en 1951 estas conocidas palabras programáticas, Vicens conocía ya el España en su historia (1948) de Américo Castro, y pensando — se halla dicho - en esa obra, en la pidalina acerca de la denominada «idea imperial leonesa», en la de José María Jover acerca de 1635, y acaso también en alguno de los primeros libros de Maravall o en Franceses, Protestantes, Turcos de Juan Sánchez Montes (1951), hablaba de las «doscientas frases cogidas al vuelo» que desconocen la densidad de realidades constitutiva de toda vida histórica y de todo pasado. 
El propio Vicens reseñó luego la primera edición del texto renovado por don Américo La realidad histórica de España (1954), y manifestó en ese momento respecto a la obra algo que tenemos por bastante exacto, aunque como muchas verdades - duela tener que reconocerlo: «La aportación de textos es considerable. Sin embargo la obra nos da sólo una parte -incluso, una mínima parte- de la realidad histórica española, tanto en el aspecto territorial y cronológico como en el de las masas que la integraron. De hecho, es la realidad de unos círculos mentales minoritarios, y por lo tanto raya en el defecto del «ideologismo» (supervaloración de textos literarios o documentales sin soporte estructural efectivo)» (Vicens1955-1956: 4). A su vez y en referencia a La España del Cid de Menéndez Pidal, don Jaime la estima «notabilísima [...y ] hermosa obra de reconstitución histórica», aunque a la vez «de peligrosa desviación sentimental sobre supuestas concepciones ideológicas imperantes en los reinos de León y Castilla durante la Alta Edad Media» (Vicens1967: 16-17).

En la búsqueda de una Historia que sea «completa» y acoja la complejidad real de la historia, Vicens estima que el materialismo resulta evidentemente unilateral, y que el positivismo de los puros datos externos no es sino esquemático; el mismo punto de vista parcial ofrece este llamado «ideologismo». Ciertamente lo ofrecido por Américo Castro en tanto «realidad histórica» de los españoles es una parte muy limitada de tal realidad, y eso llevó a Eugenio Asensio a manifestar desde el título de uno de sus volúmenes que la España descrita por don Américo era una «España imaginada» por él; el maestro brasileño-granadino pensó que la consistencia histórica del vivir de los españoles quedó clausurada con la expulsión en 1492 de los judíos, el cual vivir resultaría perdurablemente conflictivo desde entonces poco menos que para siempre, y desatendió asimismo al Setecientos y al Ochocientos (Constituciones, burguesía, obrerismo, oligarquías, ferrocarriles, mercado único, etc.) y al primer tercio del siglo XX, de enorme crisis entre nosotros desde 1909/1917: se preguntó por qué los españoles se mataban unos a otros en la gran guerra civil del año 36, y paradójicamente no buscó las causas de ese porqué en los resultados de las Desamortizaciones, en las condiciones de vida obreras y campesinas, en el analfabetismo, en la oligarquía y el caciquismo, en los egoísmos de clase, en el papel ambiguo de la Iglesia y su resultado la descristianización de las masas, en la vigencia de los peores valores del denominado «moderantismo», en la táctica de la «acción directa», ...

Según se puede observar y ha enfatizado con motivo Isabel Burdiel, sucedió que «la afirmación política del liberalismo en España, incluso del liberalismo moderado, necesitó de un altísimo grado de violencia» (Burdiel 2010: 185).

La obra de don Américo es un grito angustiado acerca de una España en la que estimaba cómo siempre (y en particular en 1939) ganaban los mismos, los mayoritarios y socialmente egoístas e ideológicamente intransigentes; es un grito en favor de las minorías consideradas «heterodoxas» del pasado español (erasmistas, ilustrados, krausistas, el grupo de Ortega).

Reseñemos en fin cómo Jaume Vicens creía que «la Historia debe definir las sucesivas mentalidades del pasado» (1967: 528), y —según queda ya reco- 
gido- que «resulta provechoso explorar las capas ideológicas, jurídicas, sentimentales, estéticas, religiosas y morales de un pueblo». En referencia a la empresa colectiva planeada y dirigida por él Historia social y económica de España y América, manifestaba: «La tarea esencial de esta obra [consiste en] definir la mentalidad de las diversas clases sociales. [...] La mentalidad social no puede definirse en cuanto arma de combate o de propaganda (aunque bueno es conocerla como reflejo de una actitud vital), sino como resultado liso y llano del proceso de relaciones humanas» (1957: 20). Creemos por nuestra cuenta - y de manera más decidida de lo que parece enunciar Vicens-, que la mentalidad es actitud vital y resultado social, y puede ser a la vez arma de propaganda y combate.

\section{El 27}

Melchor Fernández Almagro fue claramente un hombre del 27, coetáneo y amigo desde la juventud de García Lorca y de los poetas también coetáneos. Estudioso de la literatura, crítico asimismo de las letras en revistas y periódicos hasta sus días últimos, tiene en su haber una obra acaso más sólida como historiador; fue un historiador tradicional de los hechos políticos, pero serio y riguroso en todas las obras que no se vieron afectadas por el ambiente franquista de los primeros años cuarenta: varios de sus textos historiográficos conservan vigencia completa, aunque de alguna colaboración periodística en efecto cercana al franquismo, se dolió amargamente la familia García Lorca.

Melchor Fernández Almagro fue — digámoslo así— el historiador de la generación literaria del 27, aunque el gran historiador de esa cohorte fuese don Claudio Sánchez Albornoz, cuya obra inmensa reclama por ella misma una amplia monografía; por igual el lingüista representativo acaso del 27 (por la amplitud de su temática, de sus miras), es Amado Alonso. Lo que hay de interés por los poetas de su edad en Fernández Almagro; de formalismo en los análisis literarios de los dos Alonso - don Amado y Dámaso Alonso—; de vanguardismo en la crítica del primer Guillermo de Torre, autor en los años estalinistas tan defensor de la libertad («Problemática de la literatura»); de ese mismo vanguardismo en algunas de las conferencias de García Lorca; de comparatismo formal entre las artes en Valbuena; de interés por la lírica llamada de tipo tradicional en el mismo Dámaso Alonso y en José Fernández Montesinos; de gusto en don Amado por Neruda y por Lorca; ...; todo esto es Veintisiete, responde a los caracteres intelectuales que tuvo el 27. Sánchez Albornoz por su lado, enlaza más — en parte- con el modo historiográfico de Menéndez Pidal, aunque idealizase mucho menos el pasado que don Ramón.

La factura de la Historia escrita por el granadino Fernández Almagro se retrotraía al positivismo, pero al buen positivismo, al registro más exacto posible de la Historia política, de la misma manera que Amado Alonso cultivó el más estricto positivismo en cuestiones de fonética y de historia fonética. Don Melchor es una figura intelectual de interés que necesita todavía - creemos- una buena monografía sobre su obra poligráfica; de él se ha escrito por Ignacio Peiró y Gonzalo Pasamar: «Simpatizante de Antonio Maura [...].En la posguerra no 
ocupa cargos de responsabilidad política y llega a rechazar el de Gobernador Civil. Adversario intelectual de los seguidores de Menéndez Pelayo, simpatiza con los planteamientos de autores como Laín Entralgo».

\section{De nuevo el 36: sentido de la obra de J. A. Maravall}

Según queda dicho, debe ampliarse a otros campos de la vida intelectual a más de la lírica - este nombre de «generación del 36» surgido en la poesía; tal generación ha resultado de gran relieve en el desarrollo de las ciencias humanas durante aproximadamente la segunda mitad del siglo XX en España.

Esta generación española del 36 —asimismo queda apuntado- enlaza más bien con la del 14 que con la del 27, es menos formalista y estetizante que la de la Vanguardia, y posee contenidos de ideas como la de 1914; enseguida se nos viene a la memoria el nombre por ej. de Julián Marías (del 36), que encuentra a su maestro en don José Ortega (del 14).

Además de José Antonio Maravall, eran coetáneos suyos y se hallan adscritos a la misma generación otros historiadores como Antonio Domínguez Ortiz; el varias veces mencionado y citado Jaume Vicens Vives, más su discípulo Joan Reglà; Julio Caro Baroja (también etnólogo y folclorista); Manuel Tuñón de Lara; José María Jover; ... Filólogos fueron Rafael Lapesa, Emilio Orozco Díaz, o Alonso Zamora, acerca de quien parece haberse generalizado un equívoco: se le adscribe al «Centro de Estudios Históricos» de la JAE, pero nunca figura en su documentación, ni en los testimonios de los contemporáneos (Rafael Lapesa, etc.); al joven Alonso la guerra le impidió con mucha verosimilitud ingresar de manera formal en ese CEH.

José Antonio Maravall tiene esbozado el perfil del conjunto de su obra en los párrafos de «Prólogo» a uno de sus textos mayores, Estado Moderno y Mentalidad Social (1972); en cualquier caso, se trata de una obra escrita muy extensa, sólida y sugerente, posible nada más que con una amplia dedicación al trabajo intelectual: esa obra la integran unos veinticinco volúmenes - varios enormemente amplios-, más artículos nunca recogidos en libro, introducciones a reimpresiones de clásicos del pensamiento político, textos de discursos o conferencias, prólogos, etc. Tal como destacó Rafael Lapesa en la necrológica que acerca de don José Antonio publicó a su muerte en el $A B C$, buena parte de su obra intelectual hubo de hacerla sin poder contar con las mejores condiciones de salud, debido a unas relativamente tempranas dolencias cardíacas, por lo que el logro de varios de sus textos constituyó en verdad una tarea «heroica».

Maravall explicaba en el «Prólogo» aludido:

Una gran parte de nuestra labor de investigación [...] ha estado orientada al análisis e interpretación de los procesos históricos que confluyen en el amplio curso del mundo moderno. [...] Dos grandes sectores nos han interesado siempre con preferencia: la visión de la historia que ha inspirado a los hombres de 
esos siglos modernos[,] y la concepción del sistema de Estados en que sus sociedades aparecen instaladas. [...]

Una interpretación de la historia que desde una mirada al pasado se esfuerza en adivinar el porvenir; un régimen de Estado que engloba [...] el tejido de relaciones estructurales de variado tipo, establecidas en el seno de una sociedad [...]. Estos son los dos grandes temas en que se ha ocupado nuestra labor historiográfica (Maravall1972: 3).

Nuestro autor efectivamente ha analizado en los primeros siglos modernos dos cuestiones: la percepción de lo histórico, del lugar de unos hombres en la historia; y el régimen del Estado, y a ellas responden respectivamente los amplios tratados Antiguos y Modernos y Estado Moderno...

Maravall insiste en la explicación de su obra con palabras como estas:

Nuestra tarea investigadora se ha dirigido a esclarecer los dos procesos, en gran medida paralelos, de inserción del hombre moderno en la historia — vista por él como un acaecer en el tiempo, orientado progresivamente hacia adelante[,] y en el Estado —régimen específico de autoridad y libertad, que afecta a todo el ámbito de la vida social directa o indirectamente, pero siempre con innegable eficacia, desde la economía a la ciencia, desde la burocracia a la religión (Maravall1972: 4).

El asunto de «el sentido y estimación que se atribuyen al paso de la historia» señala el autor que es lo abordado en Antiguos y Modernos, mientras la obra sobre el Estado moderno y sus mentalidades sociales aborda la otra temática aludida: ya está apuntado.

Hechos e ideas se interpenetran en el acontecer histórico, y de ahí que nuestro autor estime en tal acontecer los unos y las otras en su interrelación: escribe así cómo debe admitirse que «metodológicamente el pensamiento es un dato tan positivo como pueda serlo la nutrición. [...] Nuestra obra [se refiere en particular a Estado Moderno...] constituye un intento, reflexivamente continuado, de buscar la realidad histórica en un plano de fusión de ambos elementos», las ideas y mentalidades más las realidades ocurridas, los hechos (Maravall1972: 6).

De modo muy nítido, don José Antonio manifiesta por igual que resulta «una injustificada abstracción hablar de relaciones materiales de producción; no hay nada que no lleve un inseparable contenido mental. El hecho en la historia va siempre acompañado inescindiblemente de su versión en la mente de quienes lo han vivido» (Maravall1972: 7).

Si no se tienen presentes los datos repetidos que indican un hecho de mentalidad junto a las cosas que han acaecido, no se llega a constituir - estima Maravall - una verdadera «ciencia positiva», esto es, una ciencia (positivamente) verdadera. 
En su otro libro La literatura picaresca desde la historia social, el autor insiste en que se debe llegar en la historiografía «a clarificar la imagen del «tejido mental» sobre el que ha discurrido el acontecer histórico de una época» (Maravall1986: 8).

El Estado de los primeros siglos modernos albergó en su seno - entre nosotros - mentalidades sociales, discursos sociales, que (apoyado en distintas fuentes) José Antonio Maravall tipificó y analizó: los discursos respectivos de «los integrados», los «reformadores» 0 «integrados críticos», y «los discrepantes activos»: el discurso integrado es el del teatro, el de la «comedia» española; el de los discrepantes o anómicos, el de la picaresca; reformadores o integrados de manera crítica fueron - en el concepto de nuestro autor - «Saavedra Fajardo, Gracián, Quevedo» ... (Maravall1986: 9-10). A cada uno de los términos de esta tipología dedicó nuestro autor un libro o un conjunto de artículos, y acerca de la materia escribía asimismo, por ej.:

La literatura — superlativamente el teatro y la novela picaresca— no es retrato, mas sí testimonio en el que se refleja una imagen mental de la sociedad; [... la literatura] nos traslada el conjunto de creencias, de valoraciones, de aspiraciones, de pretensiones que se reconocían en el mundo social y aquellas atrevidas negaciones de las mismas en las que se estimaba desmoronarse gravemente el sistema establecido. Las versiones de la literatura venían a definir y a dar expresión a los temores que, según la estimación de los conformistas, se provocaban en la esfera de relaciones entre individuos de estratos diferentes (Maravall 1986: 13).

No se entienden bien aisladamente los libros de don José Antonio dedicados a lo que en términos generales podemos denominar de «análisis literario», si no se tiene presente esta tipología respectiva ya mencionada: el discurso integrado o conservador del teatro; el anómico de la picaresca; y el acomodado a veces críticamente de un Quevedo, etc. Todo esto se halla referido en general al siglo del Barroco, y en este sentido ha de entenderse en el marco además de lo que reconstruye Maravall en su obra La cultura del Barroco (1975), pero nuestro autor se refirió asimismo a literatura e historia social y de los discursos en sus celebradas monografías acerca de «La Celestina»y el «Quijote».

Mucho de Historia del pensamiento político se contiene en los cuatro volúmenes densos y llenos de sugerencias de Estudios de Historia del pensamiento español; a propósito en particular de ellos escribió José Álvarez Junco que el legado de nuestro autor resultaba «abrumador». Otro libro bien instructivo y bello fue el dedicado a Carlos $V$ y el pensamiento político del Renacimiento, casi coetáneo de una monografía que hizo José María Jover en torno a «Carlos V y los españoles»: ambos textos son complementarios para el estudio del Imperio carolino, y ambos guardan mucha calidad.

A la misma época de primeros lustros del Quinientos se hallan referidos dos de los textos más celebrados por los lectores de don José Antonio: el que trata 
de las Comunidades castellanas (1963), y el que interpretaba y está mencionado «La Celestina»(1964).

Dos de los últimos volúmenes de nuestro autor fueron el que abordó el utopismo del Quinientos (Utopía y reformismo en la España de los Austrias, 1982), y el referido otra vez a aspectos de la cultura del Barroco Poder, honor y élites en el siglo XVII, 1979, texto que Antonio Domínguez Ortiz tenía por muy sugerente.

El escritor y colaborador de José Antonio Maravall en su cátedra José Antonio Gómez Marín, ha llamado la atención acerca de que hay una materia «-la Historia del pensamiento político español—que sólo su saber [de J. A. M.], su imaginación y su formidable capacidad de trabajo consigui[ó] ordenar por vez primera entre nosotros»; el logro de don José Antonio reside en sus hallazgos desde luego, mas asimismo «en el mérito de constituir, en su conjunto, el primer proyecto serio de construir esa historia desconocida o deformada que en numerosos aspectos concernía a autores y obras olvidados», de tal manera que Maravall — prosigue Gómez Marín - «nos enseñó a buscar la razón del pasado, no solamente en el eco de los clásicos, sino en la letra olvidada de tantos españoles como no han cabido casi nunca en la memoria nacional» (El Mundo, 13-VI-2011).

De su parte Pedro Laín tenía escrito antes cómo Maravall poseyó intelectualmente una «doble vena Menéndez Pidal-Hautes Études» (Gaceta Ilustrada, 28-IV-1974)

$$
\text { *** }
$$

El autor de estas páginas fue alumno alguna vez de las aulas de don José Antonio, y muchas veces de su conversación y sobre todo de sus libros: nuestros estudiantes bien lo saben.

Pero a don José Antonio, hombre bueno y sabio, no siempre se le ha respetado en el marco de la filología; lo sabemos por haber sido testigos directos de alusiones personales injuriosas y de intentos maximalistas de descalificación intelectual; por nuestra parte, queremos guardar hacia él una fidelidad no beata, sino lo más inteligente posible.

Otro de nuestros maestros fue asimismo Rafael Lapesa - en las aulas del Colegio Libre de Eméritos, en la conversación y en sus libros-; por eso vamos a acabar con unas palabras de Lapesa, referidas precisamente a Maravall cuando se fue de entre nosotros el 19 de Diciembre de 1986 y hablaba entonces del «sabio historiador de ideas y realidades, reconocido como maestro desde Minnesota hasta Venecia, el caballero de perfecta cortesía, el hombre generoso en su amistad. [...] Pero José Antonio Maravall seguirá viviendo en su obra y en nuestro recuerdo; y el rendimiento que dio a los talentos recibidos tendrá más alta y efectiva recompensa sin término» $(A B C, 21-X I I-1986$, aludido antes).

Nuestro autor era un cristiano creyente; una tarde me hablaba en su casa del Concilio Vaticano II: ha sido una coincidencia feliz que el día en que se cumplían cien años de su nacimiento, fuese el de la bella fiesta de Pentecostés, la festividad para los creyentes del Espíritu Santo. 


\section{APÉNDICE DOCUMENTAL}

Dado su atractivo intelectual, reproducimos seguidamente el Programa que explicaba el prof. Maravall en su cátedra de «Historia del pensamiento político español» de la Facultad de Ciencias Políticas, Económicas y Comerciales de la UCM, a mediados de los años sesenta.

Lección 1. El proceso de romanización-Los escritores hispano-latinosLucio Anneo Séneca: la filosofía estoica y la noción del derecho natural.- - Lucano y su concepción, de la Historia de Roma-Marcial y el orto del sentimiento hispánico.-Los panegíricos de los emperadores hispanos.

Lección 2. Romania y el sentimiento político particular de las provinciasCristianismo y patriotismo: Prudencio-Los nuevos problemas políticos del cristianismo en el Imperio: Osio y la distinción entre potestad eclesiástica y potestad civil-La interpretación cristiana de la Historia y la formación de la idea política de humanidad: Orosio.

Lección 3. El pensamiento político en la etapa de los visigodos. - Iglesia y sociedad política: los conceptos de justicia y paz en San Isidoro- Otros escritores hispano-visigodos - Aparición de la Historiografía propiamente hispánica: Idacio, Juan de Biclaro, San Isidoro, San Julián de Toledo.- Los colaboradores hispanos de Carlomagno.

Lección 4. La cultura mozárabe como sustrato hispánico-Sus manifestaciones principales y su influencia en la cultura de la Alta Edad Media. La tradición de la herencia goda como mito político en los reinos peninsulares.

Lección 5. La concepción política de nuestra historia y el programa de reconquista.-España y el problema del Islam español.

Lección 6. La idea de reino en la Alta Edad Media-La peculiar estructura de los reinos hispanos - La figura del rey.—-Las ideas de justicia y seguridad.Libertades y libertad en la vida urbana medieval.

Lección 7. El «Regnum Hispaniae» y la idea imperial hispánica-Sus distintas fases.-La penetración de la idea europea del Imperio-La fórmula de la exención y su relación con el sentimiento de la propia comunidad: Lucas de Tuy y Rodrigo de Toledo.

Lección 8. Pensadores hispanomusulmanes. - Ibn Hazm y su significación en la cultura medieval española-Avempace-Ibn Tufail.—Averroes: libertad y poder, justicia y derecho.-Pensadores hispano-judíos: consideración especial de Maimónides.

Lección 9. Del régimen feudal al régimen corporativo.-Influencia del romanismo. - Territorio, naturaleza, corporación — La obra de Alfonso X-Feudalismo y romanismo en el pensamiento de Pedro Albert.

Lección 10. Racionalismo y universalismo en la Alta Escolástica-Raimundo Lulio: su programa de reforma intelectual y su utopía política.-La influencia del lulismo. 
Lección 11. Las traducciones orientales y la literatura político-moral de apólogos y ejemplos.- Su difusión en Europa y su desarrollo en España.- - Los «espejos de Príncipes». —Gil de Zamora. —El «De Regimine Principum» del infante Pedro de Aragón.-El orden estamental en el pensamiento del infante don Juan Manuel.

Lección 12. La recepción del aristotelismo.-García de Castrojeriz.-La primera construcción científica de la política: Sánchez de Arévalo.- - Visión de la Historia de España al final de la Edad Media-El pensamiento histórico político de Ibn Jaldun.

Lección 13. La aportación de los canonistas al pensamiento moderno del Estado.-El Derecho Canónico en San Raimundo de Peñafort.-Articulación de poder real y autoridad pontificia: Vicente Hispano y Lorenzo Hispano.-La posición teocrática de Alvaro Pelayo: su «Speculum Regum». Juan de Torquemada: la «Summa de Ecclesia» y la fórmula de la «vía media».

Lección 14. El pensamiento de Eximenis como manifestación de la cultura de las ciudades. - Sustantividad y supremacía de la comunidad: la idea de «cosa pública» y el individuo-El problema de la riqueza.

Lección 15. La crítica social: el Canciller López de Ayala y su «Rimado de Palacio».—Las ideas políticas en la literatura prehumanista.-Espiritualismo y profetismo: Arnaldo de Vilanova y otros-Las corrientes de «libertad cristiana».-Los tratados sobre el tirano-El «Libro de los pensamientos variables».

Lección 16. La corriente democrática estamental en la doctrina y en las Cortes-La fórmula «quod omnes tangit».-El tratado «De optima politia» de Alonso de Madrigal.-Conciliarismo y anticonciliarismo.-El problema del voluntarismo y del nominalismo en España.-El pensamiento del bachiller Alfonso de la Torre.

Lección 17. La formación del Estado moderno.-La racionalización del aparato estatal.-La configuración del poder absoluto.-El papel del derecho y la obra de los juristas.-Burocracia y técnica.

Lección 18. La transformación del orden estamental.-Tendencias de igualdad (La polémica sobre los estatutos de pureza de sangre).—La aparición de la figura del burgués y el problema de la burguesía en España.

Lección 19. Ejército y Estado en el Renacimiento-La concepción escolástica de la guerra legítima (López de Segovia).-Del ideal caballeresco al nuevo arte de la guerra: Enrique de Villena, Alonso de Palencia, Gonzalo de Ayora.La primera influencia de Maquiavelo: Diego de Salazar.

Lección 20. El pensamiento político en la guerra de las. Comunidades. Las ciudades y el Estado.—La posición constitucional del estado llano y la lucha en torno al principio de representación política.-Los aspectos sociales del conflicto.-Alonso de Castrillo y su «Tratado de República».

Lección 21. Humanismo y Renacimiento en España-La idea imperial en la conciencia española del siglo xvi-Una interpretación tradicional. Ulzurrum.-El problema de Europa y las grandes monarquías_Luis Vives: Reforma 
del saber, del individuo y de la sociedad: la «política cristiana» como problema renacentista.

Lección 22. La corriente de reforma espiritual y el erasmismo: Alonso de Valdés.—El pensamiento utópico del obispo Guevara.—La «Institución del Príncipe cristiano» de Felipe de la Torre.-El platonismo de Jerónimo Merola.

Lección 23. La restauración renacentista del aristotelismo.-La filosofía natural como base de la ciencia política: Ginés de Sepúlveda.-Influencias del averroísmo paduano.-La doctrina de la hegemonía en el orden internacional.

Lección 24. La Escuela de Salamanca.-Francisco de Vitoria: La teoría del poder: Soberanía y orden internacional.-Domingo de Soto: el individuo y el orden político-Vázquez de Menchaca y otros juristas.

Lección 25. El descubrimiento de América en la Historia del pensamiento político.-La concepción política del espacio y del individuo.-El cosmopolitismo y la relativización del concepto del orbe-El exotismo y la comparación de los sistemas políticos._Fernández de Oviedo._Las Casas.—El Padre Acosta.-Otros escritores.

Lección 26. La aparición de la corriente del primitivismo y la organización de una sociedad ideal.-Utopía y Renacimiento.-El pensamiento utópico suscitado en relación con América.-Fray Juan de Zumárraga._- Vasco de Quiroga.-Los franciscanos en Nueva España.

Lección 27. La Reforma católica y el pensamiento de los jesuitas.-El Padre Luis de Molina. - La Ley natural y su manifestación histórica; sociedad y orden político: individuo, derecho, poder—El Padre Gabriel Vázquez y la teoría de la ley humana.

Lección 28. Suárez y la construcción del orden político interno-La teoría del poder y las categorías de razón, ley y fin-Comunidad y cuerpo místico.Suárez y las polémicas político-doctrinales de su tiempo.

Lección 29. Ideas políticas del Padre Juan de Mariana: el concepto de leyes fundamentales en la democracia estamental.-República y comunidad; sentimiento nacionalista.-El problema de la articulación entre moral, política y economía.

Lección 30. El desarrollo de la concepción técnica de la política.-La obra inicial de Furió Ceriol.-La corriente realista en Antonio Pérez.-Alamos de Barrientos y la idea de la política como ciencia empírica.

Lección 31. El pensamiento político en relación con la situación económica de la época.-Los escritores economistas, y los nuevos problemas sociales. - La disputa sobre las reglamentaciones de pobres-El programa de reforma social de Pedro de Valencia. 
Lección 32. El auge de las fuerzas de reacción y el restablecimiento de los poderes señoriales en el siglo xvii.-La tensión entre el estado social y el individualismo moderno.-Los condicionamientos sociales del Barroco.

Lección 33. La cultura del barroco y los caracteres del pensamiento político en el siglo xvii.-Los problemas de la literatura de emblemas-Psicología, Pedagogía y Política.

Lección 34. La antropología política en el pensamiento barroco. Pesimismo y pragmatismo en la visión del mundo social. - La obra de Gracián y su significación en la crisis del hombre moderno.

Lección 35. La construcción jurídica de la doctrina de la soberanía.- La influencia de Bodino.-Cerdán de Tallada.—Tovar y Valderrama—Ramos del Manzano-Proyección sobre los problemas de América.-Solórzano. Lección 36. El maquiavelismo interpretado como destrucción del orden político-La doctrina de la doble razón de Estado.-Rivadeneyra.-Quevedo-El senequismo del siglo xvii y su proyección política.

Lección 37. El tacitismo en el ambiente intelectual de la época-Difusión de la obra de Tácito en traductores y comentadores. - La corriente política de los tacitistas.-Maquiavelistas en España: Mártir Rizo; Rodríguez de la Encina.

Lección 38. El pensamiento de Saavedra Fajardo.-La figura del príncipe político y cristiano.-La prudencia política y su desarrollo en el pensamiento historicista del barroco.-La unidad de Europa en la época de la diplomacia «clásica».

Lección 39. La idea de Monarquía y su condicionamiento histórico en nuestros escritores del siglo xvii.-Los problemas de organización de la Monarquía-Consejos, Ministros y Secretarios-La dualidad Rey y Reino: el pensamiento acerca de las Cortes.

Lección 40. Panorama social del siglo xviii.-Sus aspectos demográfico, económico y técnico.-La transformación de las clases sociales y su diferente participación en el desarrollo de la sociedad ilustrada.

Lección 41. La penetración del pensamiento moderno en España-El nuevo concepto de naturaleza y el desarrollo de las ciencias naturales: Martín Martínez, Zapata, Piquer.- - La ciencia de la investigación del pasado. La teoría de la Historia.-La idea de civilización y los orígenes del historicismo: Flórez, Masdeu, Andrés.

Lección 42. La obra crítica de Feijoo.-Política y educación.-La reforma de la enseñanza como programa de gobierno.-La influencia del enciclopedismo en España (Peñaflorida, Meléndez Valdés, Montengón).

Lección 43. El despotismo ilustrado.-Campomanes.-Floridablanca.Otros escritores.-Poder real, Estado y sociedad-El despotismo ilustrado como fase en el proceso de la homogeneidad nacional._La cuestión del regalismo. 
Lección 44. La Escuela del Derecho natural y de gentes-La «geometría política» de Pérez y López-Corriente europea y posición tradicional-Marín y Mendoza, Pérez Valiente, Lázaro Dou.—Crítica del racionalismo: Cevallos y los escritores de la línea escolástica.

Lección 45. Crítica de los estamentos tradicionales.-Las manifestaciones de un espíritu burgués-Reforma económica y libertad.—El principio de utilidad social y la idea ilustrada de felicidad.-El desarrollo de las formas de vida burguesa (Ustáriz, Capmany, Foronda).

Lección 46. La polémica sobre la cultura española y el sentimiento de nación.-Cadalso y el problema del carácter nacional.-Forner y los intentos de sistematización de la Constitución española.-La cuestión del Derecho nacional: Sempere.

Lección 47. Tendencias de reforma política.-Las primeras manifestaciones de un liberalismo democrático: Ibáñez de la Rentería.-Cabarrús.— Las «Cartas económico-políticas al Conde de Lerena».

Lección 48. Jovellanos en la encrucijada de la época-Tradición y renovación.-Patriotismo, cultura y bienestar-La idea de la Constitución histórica.Las ideas de soberanía y supremacía.-El problema de la reforma constitucional.- Rey soberano y representación, como balanza política.

Lección 49. Las repercusiones de la Revolución Francesa en España.- La difusión de las ideas revolucionarias-El pensamiento político en la crisis de la guerra de la Independencia.-Flórez Estrada—Otros escritores.

Lección 50. Las doctrinas politicas de los doceañistas y la Constitución de Cádiz.—Libertad y libertades-La discusión sobre la libertad de imprenta.

Lección 51. La tensión política entre Razón e Historia.-Martínez Marina: la transmutación de los conceptos revolucionarios por el método histórico.Contrato social, soberanía, forma de gobierno.-Derechos individuales-Constitucionalismo de vía media.

Lección 52. La revolución de 1820.—-Su influencia en el extranjero. — La significación de Riego.- - La intervención extranjera y el exilio de los liberales.-La huella del movimiento revolucionario en el proceso de transformación social.-El romanticismo político.

Lección 53. La reacción frente a los principios revolucionarios.-La interpretación de Hervás.-El constitucionalismo tradicional del padre Alvarado.El obispo Vélez y la alianza del Trono y el Altar.-El absolutismo extremado del padre Vidal.

Lección 54. Los comienzos de una consideración sociológica de la política.-Bentham en España.-Núñez y el utilitarismo.—El radicalismo burgués y constitucional de Ramón Salas.

Lección 55. Los inicios del pensamiento conservador.-Gómez Hermosilla, Javier de Burgos.-El romanticismo de Martínez de la Rosa. 
Lección 56. Los orígenes del pensamiento liberal en torno a la Constitución de 1837.-El progresismo de Olózaga, Mendizábal y otros.—Los comienzos del periodismo político.-Larra, Espronceda.

Lección 57. El doctrinarismo en España.-La filosofía ecléctica de García Luna.-La concepción política de los doctrinarios como régimen del «siglo mercantil»: Alcalá Galiano.-Concepción burguesa del papel político de la aristocracia: Pacheco—La introducción del Derecho politico en la Universidad: A. de la Quadra.

Leccción 58. Balmes y las corrientes ideológicas de su tiempo.-La idea de sociedad como categoría política.-Constitución interna y estructura social.La organización del gobierno representativo, los problemas electorales y la opinión pública.

Lección 59. Donoso Cortés.-Las fases del pensamiento donosiano: de la soberanía de la inteligencia a la teología política decisionista.- La antinomia entre razón y voluntad.-Teoría de la dictadura-Donoso ante otros escritores españoles (Balines, Bravo Murillo; Cánovas y. Menéndez Pelayo).

Lección 60. Los cambios de la estructura social en la segunda mitad del siglo xix-. Burgueses y proletarios.-Los movimientos de 1854 y 1868.

Lección 61. La elaboración doctrinal del tradicionalismo.-Aparisi Guijarro: La libertad como costumbre.-Enrique Gil Robles y el problema político de la estructura del territorio.- - La idea de nación.-Doble concepto de soberanía.El pensamiento de Vázquez de Mella.

Lección 62. La línea del pensamiento conservador.-Moderantismo y conservadurismo: Bravo Murillo.-La introducción del régimen jurídico de la Administración.

Lección 63. La crítica del partido moderado: Andrés Borrego.—La fórmula de la «Unión Nacional».—Ríos Rosas.

Lección 64. Las posiciones doctrinales del centrismo.-La fórmula conciliadora de Pastor Díaz.-El individualismo conservador de Alonso Martínez.

Lección 65. Cánovas.--Revisión del proceso histórico español.-Estado y nación.-La fórmula de la monarquía constitucional.—Estamentalismo: soberanía y propiedad.

Lección 66. El regionalismo en su fundamentación histórica y económica.Regionalismo y proteccionismo.-El proteccionismo en los escritores catalanes.-Gamazo y el movimiento agrario castellano.

Lección 67. Direcciones del pensamiento liberal.-El liberalismo individualista y la discusión sobre libertad antigua y moderna-El liberalismo como partido: Sagasta.-Liberalismo y nacionalismo.-La influencia democrática.-La organización de una sociedad civil.-El pensamiento y la acción gobernante de Moret.

Lección 68. El catolicismo liberal.-Sus orígenes: el tomismo liberal antes de 1868. - La aceptación de las formas del constitucionalismo.- Las polémicas en torno a este tema. 
Lección 69. El liberalismo democrático de Castelar y sus polémicas doctrinales.—La fórmula del progreso.—-La libertad y los derechos individuales. Nacionalismo, soberanía popular, sufragio universal.

Lección 70. El liberalismo organicista y las corrientes sociológicas. - Los krausistas - . Pluralismo social y jurídico: Giner de los Ríos.-Azcárate.—- Las formas de gobierno, el «self-government», los partidos políticos, el parlamentarismo.

Lección 71. El radicalismo y su manifestación como partido político.- - El republicanismo como programa de gobierno.-El pensamiento de Salmerón.La formación del radicalsocialismo.

Lección 72. Las ideas democráticas de carácter social. —La obra doctrinal de Pi y Margall.-La significación política y social del federalismo-La influencia del positivismo en España y la repercusión de sus diferentes direcciones en el pensamiento político.

Lección 73. Socialismo premarxista: traducciones e influencias extranjeras-La corriente del. cooperativismo socialista.-Garrido y otros escritores.

Lección 74. Penetración y desarrollo del internacionalismo obrero.-La corriente doctrinal del anarquismo.-El sindicalismo anarquista.

Lección 75. Socialismo de influencia marxista.-Su origen y desarrollo. Aspectos de su difusión doctrinal.

Lección 76. La democracia cristiana, como fórmula de política social.- El sindicalismo católico: sus diferentes formas.

Lección 77. Análisis de la situación española al comenzar el siglo xx e interpretaciones doctrinales de la misma-Costa.—Los programas del regeneracionismo.

Lección 78. La revisión del programa liberal: Canalejas.--Su posición ante los problemas sociales, educativos y religiosos-La significación de Santiago Alba.

Lección 79. El pensamiento del partido conservador.-De Silvela a Maura.-Su posición crítica.-El programa social de Dato.

Lección 80. El reformismo político y el problema de la autenticidad nacional: Ganivet, Menéndez Pelayo, Unamuno..--Visión política de Epaña en Maragall.

Lección 81. - Las corrientes del pensamiento catalán ante los problemas culturales, políticos y económicos: Almirall, Torres y Bagés, Prat de la Riba, Rovira Virgili, Cambó.

Lección 82. De 1898 a la guerra de 1914.—La transformación de la estructura social y económica del país.-La llamada crisis del régimen constitucional y las nuevas formas del pensamiento político. 


\section{BIBLIOGRAFÍA}

BuRDiEL, I. (2010) Isabel II. Una biografía, Madrid, Taurus.

Obra basada en muy amplias fuentes documentales y además de lúcidas interpretaciones; por ej. se muestra cómo «la afirmación política del liberalismo en España, incluso del liberalismo moderado, necesitó de un altísimo grado de violencia y de movilización popular previa, un altísimo grado de afirmación de facto de la soberanía nacional sobre el trono». Etc.

Imprescindible para el Ochocientos y la centuria liberal española.

Jover ZAMOra, J. M. (1992) La civilización española a mediados del s. XIX, Madrid, Espasa Calpe.

Mencionamos el presente libro sobre todo por el texto de su segunda parte conceptual, «Por una Historia de la civilización española»; en conjunto es un volumen penetrante y agudo.

Maravall, J. A. (1967) Teoría del saber histórico, tercera ed. ampliada, Madrid, Ed. Revista de Occidente.

Una de las no muchas obras sobre el asunto que había en su momento; inteligente y perspicaz, sobre todo en esta última edición que hizo el autor. Hay reedición con estudios previos de Francisco Javier Capistegui e Ignacio Izuzquiza: Pamplona, Urgoiti, 2007.

Maravall, J. A. (1972) Estado Moderno y mentalidad social, Madrid, Eds. de la Revista de Occidente.

Amplio texto en dos volúmenes que el autor tenía por capital en su trabajo y que lo es sin más.

Obra impar en su momento, de lectura inexcusable para la materia, y que responde bien a la tradición intelectual relevante que se dio entre nosotros en los lustros anteriores a la guerra civil del 36 en la que empezó a formarse J. A. Maravall..

Maravall, J. A. (1981) [1954] El concepto de España en la Edad Media, Madrid, CEC. Obra historiográfica de gran valor, conservado más de medio siglo después de la primera edición.

Maravall, J. A. (1986) La literatura picaresca desde la historia social, Madrid, Taurus. Aportación de gran relieve asimismo, no trata de la «novela» picaresca, sino de la «materia picaresca» en la literatura, o sea, de toda la literatura picaresca. Texto no siempre entendido ni querido entender por algunos filólogos, es sin embargo de gran agudeza y brillantez.

Menéndez Pidal, R. (1957) España y su Historia, I, Madrid, Minotauro. Antología poco conocida de textos pidalinos — sin las notas, y en dos volúmenesorganizados en sistema. Recopilación útil.

Menéndez Pidal, R. (2005) Historia de la lengua española, I, Madrid, Fundación Ramón Menéndez Pidal y RAE.

Obra que Lapesa tenía por magistral, aunque inacabada —el autor la da por finalizada al llegar hasta h. 1680-; quedó escrita en lo fundamental en los años de la guerra española y la guerra mundial. No se entiende muy bien que parezca haber pasado entre nosotros un tanto inadvertida o en todo caso poco tenida en cuenta.

Valdeavellano, L. G. de (1955) reseña de J. A. Maravall, «El concepto de España en la Edad Media», AHDE, XXV, 877-890.

Amplio comentario, hecho con saber y sensatez. 
Valdeavellano, L. G. de (1982) [1968] Curso de Historia de las Instituciones españolas, Madrid, Ed. Revista de Occidente.

Obra de conjunto completa en lo que trata, lograda con calidad. Recoge aportaciones de José Antonio Maravall.

ViCEns Vives, Jaime (1952) Aproximación a la historia de España, Universidad de Barcelona.

Interpretación del conjunto de la historia española, rehecha en la segunda edición ultimada al final de la corta vida del autor.

ViCENS VIVES, Jaime (1955-1956). Reseña de A. Castro, «La realidad histórica de España», Índice Histórico Español, Barcelona, II.

ViCENS Vives, J. (dir.) (1957) Historia social y económica de España y América, Barcelona, Teide, I.

Obra de importancia, citada aquí por las páginas previas de propósitos de método.

ViCEns Vives, J. (1974) [1960] Aproximación a la historia de España, Barcelona, Edit. Vicens-Vives.

Se trata de la aludida segunda edición del texto, de lectura muy recomendable.

Vicens Vives, J. (1967) Obra Dispersa, Barcelona, Edit. Vicens-Vives, II.

Recopilación enormemente útil para acceder a muchos escritos vicentinos. 
